\title{
Voltage Security in AC Microgrids: A Power Flow-Based Approach Considering Droop-Controlled Inverters
}

\begin{tabular}{|r|l|}
\hline Journal: & IET Renewable Power Generation \\
\hline Manuscript ID: & RPG-2014-0406.R2 \\
\hline Danuscript Type: & Research Paper \\
\hline Complete List of Authors: & $\begin{array}{l}\text { Zambroni de Souza, Antonio; Universidade Federal de Itajubá, Electrical } \\
\text { Engineering } \\
\text { Santos, Marcos; Federal University of Itajubà, ISEE } \\
\text { Castilla, Miguel; Technical University of Catalonia, Electronic Engineering; } \\
\text { Miret, Jaume; universitat politecnica de catalunya, electronic engineering } \\
\text { Garcia de Vicuna, Luis; Universitat Politecnica de Catalunya, Electronic Eng. } \\
\text { Marujo, Diogo; Federal University at Itajubá, Electrical engineering }\end{array}$ \\
\hline Keyword: & POWER ENGINEERING, POWER SYSTEM PLANNING, POWER SYSTEMS \\
\hline &
\end{tabular}

SCHOLARONE $^{\text {m }}$

Manuscripts 


\title{
Voltage Security in AC Microgrids: A Power Flow-Based Approach Considering Droop-Controlled Inverters
}

\author{
A. C. Zambroni de Souza ${ }^{1}$, Marcos Santos ${ }^{1}$, Miguel Castilla ${ }^{2}$, Jaume Miret ${ }^{2}$, Luis García de \\ Vicuña $^{2}$ and Diogo Marujo ${ }^{1}$ \\ ${ }^{1}$ Institute of Electrical Systems and Energy, Federal University of Itajubá, Itajubá, Brazil \\ ${ }^{2}$ Department of Electronic Engineering, Technical University of Catalonia, Vilanova i la Geltrú, \\ Spain
}

\begin{abstract}
This paper deals with the problem of voltage security in microgrids. In general, voltage security is an issue for power systems, where the lack of reactive power is a concern. For microgrids a complexity is imposed, since frequency and voltage level deviations may take place by the operation of droop-controlled inverters. This paper incorporates the load margin calculation into a microgrid structure. For this purpose, a special power flow program is developed in order to consider the effects of the droopcontrolled inverters. Simulation results are obtained with the help of an islanded distribution system with only generators coupled by droop-controlled inverters, so the proposed methodology may be tested and discussed.
\end{abstract}

Keywords: - Microgrids, voltage collapse, power flow.

\section{Introduction}

Bulk power systems are operated in an interconnected mode in order to guarantee reliability and robustness to final users. In this sense, many studies, like dynamic and voltage stability, reliability, protection and power quality are carried out during the planning and operating scenarios. This is done in order to avoid any local event to spread into multiple areas of the system. Considering natural catastrophes, like tsunamis, makes the problem even worse, since electricity is one of the infrastructures to be preserved. Recently, due to the increasing penetration of renewable generation, such problem has gained more attention. Preserving a system after a catastrophe takes place rises the concept of a smart grid, theoretically capable of playing a self-healing process [1]. Such a new concept deserves special attention, as discussed in [2], where many aspects of smart grids, like definitions, impact, social interactions and few experiences are placed. Even normal operation conditions are also subject to an 
efficient planning strategy, which may include power forecast in order to optimize the energy storage devices $[3,4]$.

Microgrids fit in smart-grids concepts. However, unlike shipboards [5], which always work on an isolated mode, microgrids may work in an islanded manner $[6,7]$ or connected to a bulk system, though in an autonomous way [8]. A further characteristic lies on the fact that it may work in both ways simultaneously, i.e., though connected to a system, it is self-sufficient to provide its own load $[9,10]$. The architecture of microgrids is a renewable generation-based. Because many of the microsources considered can not be directly connected to the network, inverters are necessary to provide an alternate current (AC) to the network in a uniform manner, so the voltage is locally controlled and a single frequency is guaranteed $[11,12]$. This increases the complexity of the system, since new components are now necessary to be modelled and new interfaces must be understood $[13,14]$. Some papers deal with the problem of enhancing a microgrid operation by analysing the system loss and reliability [15, 16], whereas others focus on interconnecting different microgrids $[17,18]$. Little attention has been addressed, however, to the problem of voltage stability in microgrids.

In general, voltage stability takes place in power systems as a function of reactive power problems following a load increase or a fault. For this sake, many researchers have focused on proposing methods that deal with load margin calculation and critical areas determination $[19,20]$, since they play a crucial role on voltage stability studies. The advent of microgrids places new challenges, since electric plug-in vehicles may be incorporated into the system. In this sense, a recharging strategy to avoid under-voltage becomes mandatory $[21,22]$ and discussions about the policies associated with his topic are also of interest [23]. Studying voltage stability and proposing a power flow methodology for microgrids are the focus of this paper. Reference [24] has already attempted to deal with this problem by employing a multiagent system to enlarge the system load margin, whereas reference [25] proposes a continuation power flow for microgrids. However, a state-space model is employed to represent the microgrids dynamics, not focused here. In this paper, a power flow-based approach adapted for microgrids is incorporated into a continuation method. This problem is addressed in [26], where a three-phase power flow for islanded microgrids is proposed. Reference [27] proposes a load flow for islanded microgrids with no need to specify a swing bus. The system frequency is calculated in the iterative process. Searching the optimal values of the droop coefficients is addressed in [28], where the share of the reactive power supply is 
meant by using particle swarm optimization. As stressed in [26-30], formulating a Newton-based method for solving a power flow in a microgrid presents three problems:

- Frequency, though common for the whole system, is not kept constant.

- The need of a swing bus.

- Voltage level may vary in the sources.

These constraints pose an interesting challenge for microgrids structures, since islanding and emergency conditions may take place. This paper proposes a methodology to deal with this problem. In this sense, the frequency and voltage level may vary. Thus, the proposed methodology may handle a range of different operating conditions, which include droop parameters adjustments and climatic variations which affect wind and solar availability. After that, a continuation method is proposed by incorporating this power flow program. For this sake, besides the reactive power limits, other constraints are considered, making the formulation more adequate to microgrids. The idea is tested in a real system with 115 nodes and 118 branches.

\section{Control Schemes in Microgrids}

The microgrid employed here is an active power system in which the distributed energy resources are coupled only electronically, so its complexities are explored. As shown in Fig. 1., the generating devices include intermittent energy sources (such as solar panels and wind generators) and dispatchable energy sources (such as microturbines). They are connected to the grid by an inverter-based interface. This paper assumes the two possible control strategies for the operation of the inverters:

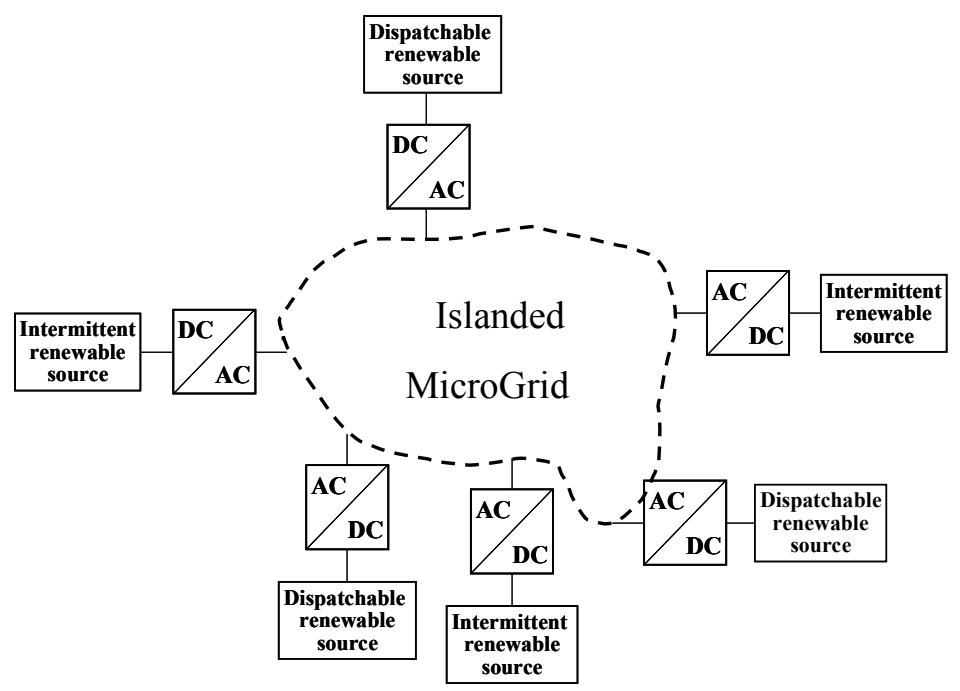

Fig 1 General diagram of a microgrid with electronically-coupled renewable energy sources 
- $\quad$ PQ mode control for the intermittent energy sources, which means that the inverters provide a pre-specified amount of active and reactive power.

- Voltage source mode control for the dispatchable energy sources. The active and reactive powers injected by the inverters depend on the system loading. Unlike robust transmission systems with capacity to control their frequency and voltage level through speed and voltage regulators, microgrid inverters for dispatchable sources use the conventional droop method. In this case, the frequency and amplitude of the inverter output voltage are modelled as [14]:

$$
\begin{gathered}
w=w^{*}-m P \\
V=V^{*}-n Q
\end{gathered}
$$

where $w$ is the frequency obtained for a load $P$, whereas $w^{*}$ is the frequency at no load. In addition, $m$ is the share of active power generation taken by the inverter. Similarly, $V$ is the voltage level obtained for a generation $Q$, whereas $V^{*}$ is the voltage level at no load condition and $n$ is the share of reactive power of the inverter.

Reference [8] proposes an enhanced droop control method that captures the system dynamics, so the time response is explicitly considered. This makes the microgrids operate close to real systems. However, it is obtained at the cost of strong connection with a bigger system. In order to exploit the possibilities of an islanded microgrid, such a control is not considered in this paper. Thus, this paper focuses on analysing the effects of voltage and frequency drops along a load pattern variation. Fig. 2 depicts the droop method employed here.

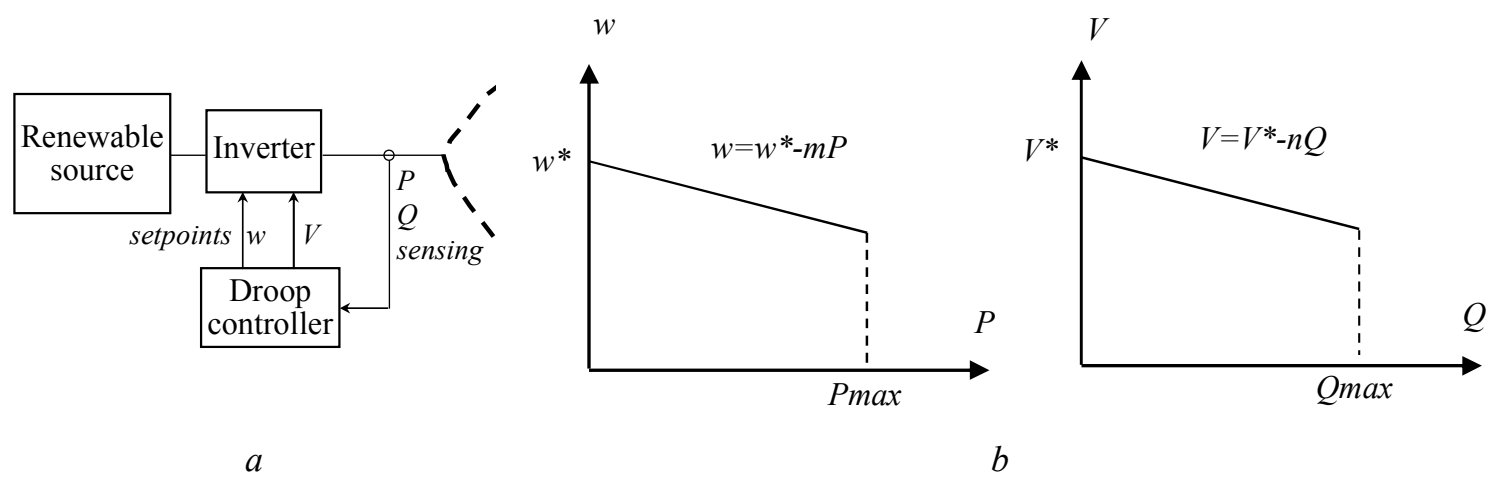

Fig 2 Droop method for the dispatchable generation inverters (a-General diagram of the dispatchable energy source, $b$-Representation of the droop method curves) 
As for droop method, the slope of the lines in Fig. 2 determines the share of the unit with respect to total generation. In this sense, the greater the slope of one unit in relation to the nominal slope, the smaller the share of that unit. Further explanation on sharing capacity is found in [12].

\section{Power Flow in Isolated Microgrids}

Power flow studies are conducted for planning and operating scenarios of power systems with the aim of studying a system operating condition. Generally, Newton's method is used for this purpose, with the help of the equations:

$$
\begin{gathered}
P_{i k}=-t G_{i k} V_{i}^{2}+Y_{i k} V_{i} V_{k} \cos \left(\theta_{i k}-\alpha\right) \\
Q_{i k}=t B_{i k} V_{i}^{2}-V_{i}^{2} B_{i k}+Y_{i k} V_{i} V_{k} \sin \left(\theta_{i k}-\alpha\right)
\end{gathered}
$$

where $t$ is the ratio between the transformer taps $t_{i}$ and $t_{k}$ at the transmission lines, $B_{\text {sik }}$ is the transmission line susceptance, $G_{i k}, B_{i k}$ and $Y_{i k}$ are the elements of the admittance of branch $i k$, and $\alpha$ is the angle between $B$ and $G$. Equations (2) and (3) are widely known, but they are reproduced here in order to help the reader understand the approach proposed in this paper.

Linearizing the above equations provides the Jacobian $J$ :

$$
\left[\begin{array}{l}
\Delta P \\
\Delta Q
\end{array}\right]=[J]\left[\begin{array}{l}
\Delta \theta \\
\Delta V
\end{array}\right]
$$

Equation (4) contains the partial derivatives of the active power equations of all buses, but one, with respect to the phase angle and voltage magnitude. The bus excluded from the formulation is the slack (or swing) bus, whose phase angle is the system reference and is responsible for supplying the system's loss. The linearization of the reactive power equations takes place for all load buses. In this sense, the generators and synchronous condensers do not have their equations considered in (4). This is because their voltage level is fixed and the reactive power generated is determined after the iterative process of (4) is over. Hence, the reactive power generated is the price paid to keep the voltage magnitude at a specified level. For basic concepts on power flow calculations, the reader is referred to [31].

Unlike transmission systems, microgrids are subject to small frequency and voltage level deviations, as shown in (1). It imposes a complexity to power flow computation as shown in (4). This paper proposes a novel approach for power flow calculation which takes into account the droop coefficients. Newton's 
method is employed, despite the fact that voltage and frequency levels vary. This is done according to the following steps:

1. The active power generation at every source is calculated according to the $m$ coefficient of (1). As usual, the frequency at no load is common for all droop-controlled inverters [13], [14]. In this sense, the total load is distributed among the generation sources with the pre-determined $m$ coefficients. This includes the swing bus, whose share in the load demand is determined by its coefficient $m$. The initial guess for voltage level and phase angle for PQ buses is also considered at this stage.

2. The mismatch from the power flow is calculated. If the error is less than the specified tolerance, stop. Otherwise, go to step (3).

3. Calculate the system's Jacobian shown in (4) and update the variables.

The variables are updated as:

$$
\begin{aligned}
\theta^{i} & =\theta^{i-1}+\Delta \theta^{i-1} \\
V^{i} & =V^{i-1}+\Delta V^{i-1}
\end{aligned}
$$

where $\Delta \mathrm{V}$ and $\Delta \theta$ are obtained from (4).

4. The reactive power generated by each source is calculated and the voltage level $V$ is updated as shown in (1). Return to Step 2.

When applying Newton's method, a slack bus is considered. Such a bus is the one responsible for supplying the system active power losses (the reactive power losses are shared by all the sources). Besides, its phase angle is the reference, so all the phase angles are calculated with respect to it. The methodology proposed here also considers the slack bus as the reference. Its active power generation is determined in two steps:

1. The system frequency is determined by (1) after the solution is obtained. This is obtained by applying (1) to any source, but the slack bus, since the system frequency is only one for the whole system. Then, the active power generated by the slack bus is also calculated, just like an ordinary power flow. Hence, the system frequency is not dependent on the swing bus.

2. Once the frequency is obtained, (1) is applied for the swing bus. This updates the $m$ coefficient of the slack bus, since this is responsible for the system's loss.

It is important to mention that the proposed methodology has been compared with the algorithm described in [27]. When the same initial conditions are considered, the results are the same, rendering both 
methodologies as suitable for this kind of study. These results have also been compared with the ones obtained in [32] when the droop parameters are incorporated into the program. Once again, the same output is observed.

An additional advantage of the proposed method regards the fact that it may be easily incorporated into an ordinary power flow program. Fig. 3 shows a flowchart of the proposed algorithm.

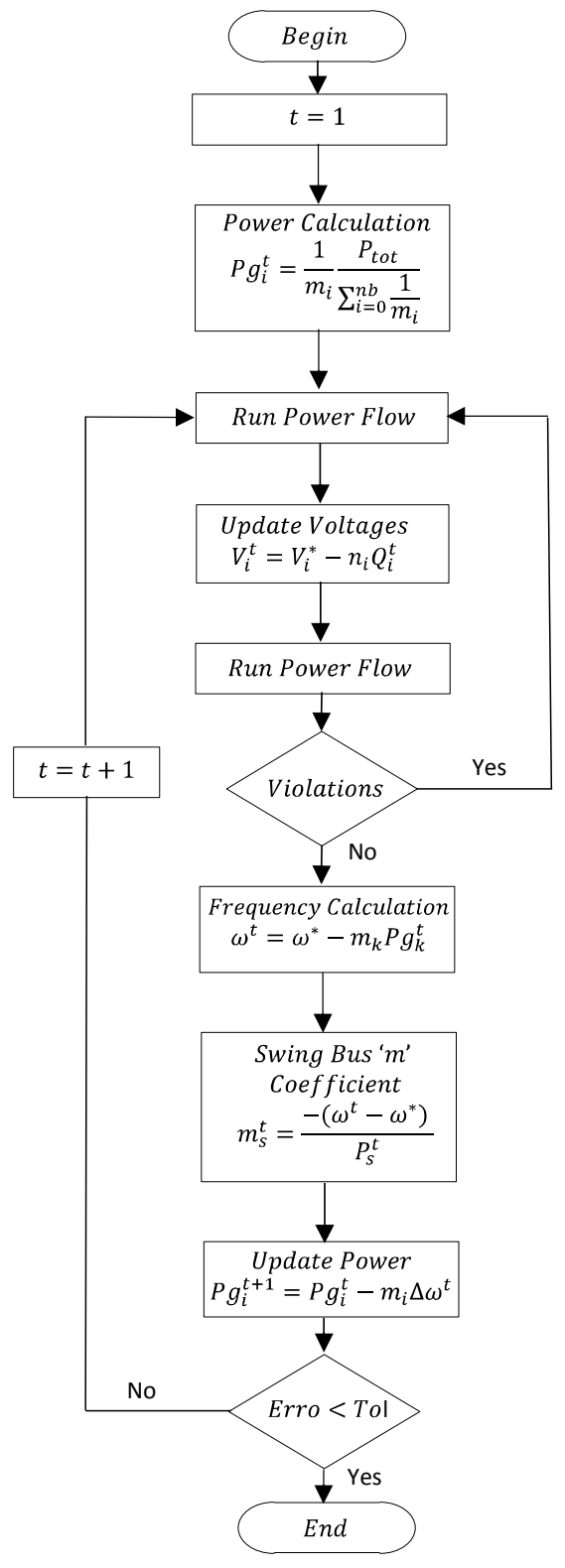

Fig 3 Flowchart of the proposed algorithm

From Fig. 3 one can see that the proposed methodology enables one to calculate a power flow to a microgrid with frequency and voltage level deviation at the sources. The results obtained are dependent on the droop parameters. For all the tests carried out here, no convergence problems have been reported. 
In general, the convergence is obtained in seven iterations for each flow. Because the continuation method migrates from one equilibrium point to another, the Newton's method tends to converge easily. Convergence problems are expected when the system approaches a bifurcation point, but special features avoid that. This, however, is not a particular problem for microgrids. Rather than that, it has been reported to gridded power systems. Next section describes some open challenges regarding voltage collapse in microgrids. These challenges have been addressed by the novel methodology proposed in this paper, so it may handle a wide range of operational complexities of microgrids.

\section{Voltage Collapse in Microgrids}

Voltage collapse became a source of concern in the last thirty years. The problem is either caused by the transmission lines constraints or lack of reactive power. This problem may become even worse for microgrids, because of its control limitations. In this case, voltage level and frequency drops may deteriorate even further the system operating conditions, driving a system to voltage or dynamic instability. When studying voltage collapse one is particularly interested in the system load margin calculation and the system critical area identification. The continuation method may be effectively employed for this purpose, especially because of its robustness and accuracy [19, 20]. This section presents the continuation method applied to microgrids. First, the general concepts of the continuation method are shown.

Continuation methods may be used to monitor the system equilibria up to a bifurcation point is found. The following system model applies:

$$
f(x, \lambda)=0
$$

where $x$ represents the state variables and $\lambda$ is a system parameter. When dealing with voltage security studies, load margin calculation plays an important role. The idea is, from an operating point, a parameter variation drives the system from one equilibrium point to another, up to a bifurcation point is encountered. Such a method is based on two steps:

1. Predictor step, which defines a direction for load and generation increase. Tangent vector may be used for this purpose [20]. Such vector comes from the power flow equations and is given by: 


$$
T V=\left[\begin{array}{l}
\frac{\Delta \theta}{\Delta \lambda} \\
\frac{\Delta V}{\Delta \lambda}
\end{array}\right]=[]^{-1}\left[\begin{array}{l}
P_{0} \\
Q_{0}
\end{array}\right]
$$

where $J$ denotes the power flow Jacobian, $\lambda$ is the system loading/generation level, and $P_{o}$ and $Q_{o}$ are vectors of the net active and reactive powers injected into each bus. $T V$ is the acronym for tangent vector. The predictor step is given by:

$$
\Delta \lambda=1 /\|T V\|
$$

where $\|$.$\| stands for the Euclidean norm. The actual solution is obtained at each loading level with the$ help of the corrector algorithm.

2. Corrector step, obtained here by considering the predictor step results as the initial guess in a conventional power flow. In general, the corrector algorithm converges rapidly to the desired operating point.

Applying the method above for microgrids is straightforward if the power flow proposed in Section 3 is employed. However, some challenges must be addressed when dealing with microgrids:

- Renewable sources must be carefully considered. This is because they are intermittent and cannot vary their generation as usually considered for dispatchable machines.

- Adjusting the droop parameters also plays a role in this process, since they are responsible for determining the generation share among the units.

- For connected mode, it is important to assess the effects of local generation, since the microgrid may export energy to the grid. The outage of some units may change this operating condition, affecting the losses and the determination of the critical buses of the system.

- For islanded mode, special considerations are incorporated into the methodology. Thus, besides under voltage level and proximity to a saddle-node, other criteria like under frequency and limitation in the droop parameters are considered in the stopping criteria.

- Because microgrids may not have enough generation to sustain a load increase, load shedding may take place in order to face this restriction. 
- In a future scenario, plug in vehicles may be considered as emergency suppliers. Actually, the literature shows a variety of papers dealing with the problem of electric vehicles charging, since this may cause loss increase and under voltage. Considering as emergency generators, however, is a point of research which is dependent on regulation issues.

\section{Test Results}

\subsection{Methodology}

The tests carried out in this paper aim to show the potentiality of the proposed methodology. The tests are divided in three parts:

1- A load flow is calculated for the base case. The critical buses under the voltage collapse point of view are identified.

2- Load margin calculation is executed. In this sense, the following considerations are taken into account:

- Firstly, load margin is calculated as normally executed for large systems. This provides an indication about how robust this system would be if connected to a large transmission network. This guarantees a regulated voltage level at the sources as long as the reactive power generation is within its limits.

- Voltage and frequency deviation are considered as proposed in Section 2. Initially, no limitation for active power generation is considered.

It is important to mention that, for the above cases, the computational process is stalled when a bifurcation point is encountered or one of the stopping criteria adopted in [20] is triggered.

- $\quad$ As an extension of the last step, active power generation at the sources and under voltage level limits are observed. This may create a lower load margin for the system. However, this is in connection with real conditions faced by microgrids.

All the cases analysed take the reactive power limits at the sources into account.

3- Then, the effects of the coefficients $m$ and $n$ used in the droop-controlled inverters are analysed.

The ideas proposed in Section 2 and 3 are then tested. For this sake, the system depicted in Appendix A is employed. It has 155 nodes, 118 branches, 2 photovoltaic sources, 3 wind generators and 8 power plants of dispatchable generation. It is important to mention that each of these plants is actually composed by a 
set of ten small units connected to an inverter. Each inverter has a $6 \mathrm{MW}$ or $3 \mathrm{MW}$ capacity and is controlled by the droop method. Therefore, the system is not connected to any huge synchronous machine. The total load stands for $1.78+\mathrm{j} 0.72 \mathrm{pu}$ calculated over the base 100 MVA. Such a base is considered as common for all the studies. Because of the inverter mode considered, the intermittent photovoltaic and wind generators provide a pre-specified value of active and reactive power. Table 1 summarizes the capacity of each intermittent energy source. In addition, Table 2 shows the capacity of the dispatchable energy sources.

As for the system employed, it is chosen because it presents some complexities important to be analysed. This is, in fact, a large microgrid with high power generation and consumption [15], [18]. According to this low $\mathrm{R} / \mathrm{X}$ ratio is considered in this study. However, the methodology proposed here is valid for small microgrids with high $\mathrm{R} / \mathrm{X}$, since a rotation in the axis may change this ratio, as explored in [32].

Table 1: Capacity of the intermittent energy sources considered

\begin{tabular}{|c|c|c|}
\hline Bus & Type & $\begin{array}{c}\text { Cap. } \\
\text { [p.u.] }\end{array}$ \\
\hline 49 & Solar & $3 \mathrm{e}-3$ \\
\hline 50 & Solar & $3 \mathrm{e}-3$ \\
\hline 71 & Wind & $20 \mathrm{e}-3$ \\
\hline 72 & Wind & $20 \mathrm{e}-3$ \\
\hline 73 & Wind & $20 \mathrm{e}-3$ \\
\hline
\end{tabular}

Table 2: Characteristics of the dispatchable energy sources considered

\begin{tabular}{|c|c|c|c|}
\hline Bus & $\boldsymbol{m}$ & $\boldsymbol{n}$ & $\begin{array}{c}\text { Max } \boldsymbol{P} \\
\text { [p.u.] }\end{array}$ \\
\hline 34 & $1 \mathrm{e}-3$ & $0.1 \mathrm{e}-3$ & 0.6 \\
\hline 46 & $1 \mathrm{e}-3$ & $0.1 \mathrm{e}-3$ & 0.6 \\
\hline 55 & $1 \mathrm{e}-3$ & $0.1 \mathrm{e}-3$ & 0.6 \\
\hline 65 & $1 \mathrm{e}-3$ & $0.1 \mathrm{e}-3$ & 0.3 \\
\hline 76 & $1 \mathrm{e}-3$ & $0.1 \mathrm{e}-3$ & 0.6 \\
\hline 81 & $1 \mathrm{e}-3$ & $0.1 \mathrm{e}-3$ & 0.6 \\
\hline 90 & $1 \mathrm{e}-3$ & $0.1 \mathrm{e}-3$ & 0.6 \\
\hline 103 & $1 \mathrm{e}-3$ & $0.1 \mathrm{e}-3$ & 0.6 \\
\hline
\end{tabular}

\subsection{Base case results and discussion}

Following the proposed procedure, a power flow is executed for the base case. The critical buses are identified, as listed below in decreasing order of relevance:

$68,67,114,115$ 
Firstly, the continuation method is applied with no limitations, which implies in considering conventional sources with voltage and frequency regulators. The program developed considers a ZIP load model, which permits one to verify the effects of voltage variation in the demand. However, a constant power model is a more pessimistic model, since the demand is invariant with respect to the voltage level. Because of this, a constant power model is adopted here. Fig. 4 depicts the active power-voltage (PV) curves of the critical buses identified above. As for the plots depicted in Fig. 4 to Fig. 7, one should note that load/generation variation considered in this paper follows the pattern:

$$
\begin{aligned}
& P=P_{0}(1+\Delta \lambda) \\
& Q=Q_{0}(1+\Delta \lambda)
\end{aligned}
$$

where $\lambda$ is as defined in (6). In this sense, the term "Loading" in the abscissa corresponds to $(1+\Delta \lambda)$ in (9).

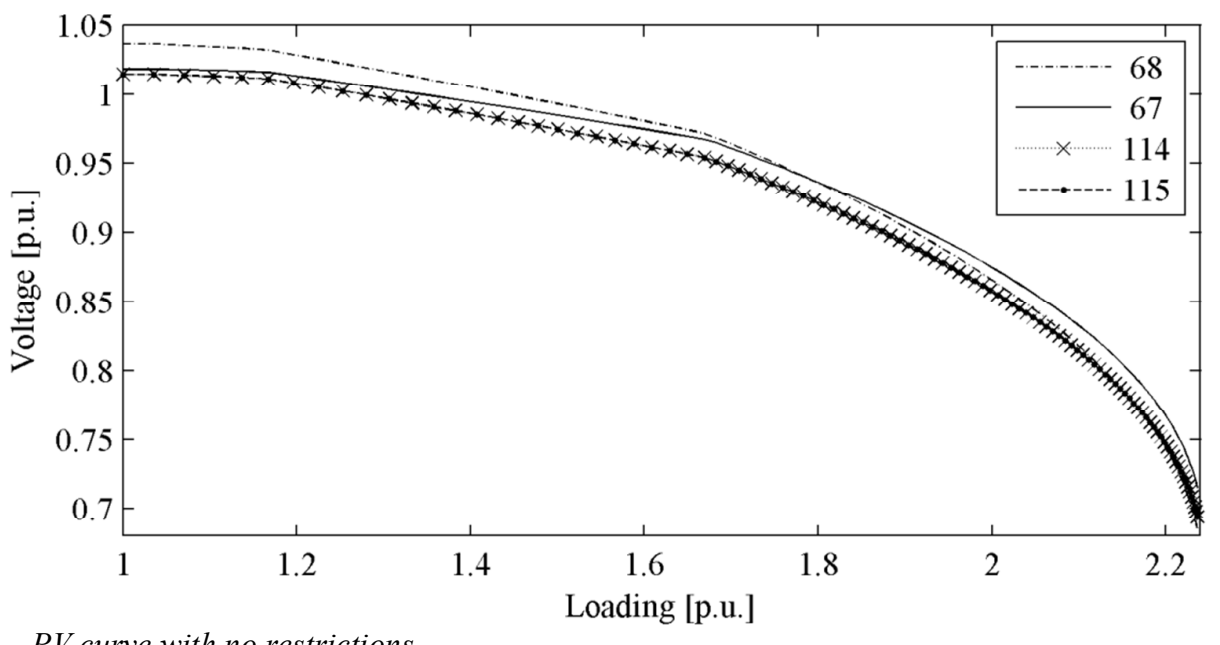

Fig. 4 PV curve with no restrictions

From Fig. 4 one can see that the system collapses at 2.24 p.u of load increase, rendering a total load about $3.98+\mathrm{j} 1.61$ p.u. Note, however, that the system is subject to unbearable voltage levels, rendering the results as unrealistic for operating purposes. This is mitigated by imposing a lower voltage level at the load buses, yielding the results depicted in Fig. 5. Note that the imposed restrictions change the critical buses compared with the ones depicted in Fig. 4. The process is set to stop if voltage level goes below 0.85 p.u. This kind of behaviour is widely known from the literature $[19,20]$. This is shown here as a step of the proposed methodology, since this is still a non-operable voltage level, acceptable only for emergency conditions. The methodology, however, may incorporate any voltage level as a trigger to stall 
the load increase process. Note from Fig. 5 that the system load margin is reduced (around 99\%) as a lower voltage level bound is imposed. In this case, no bifurcation point is observed.

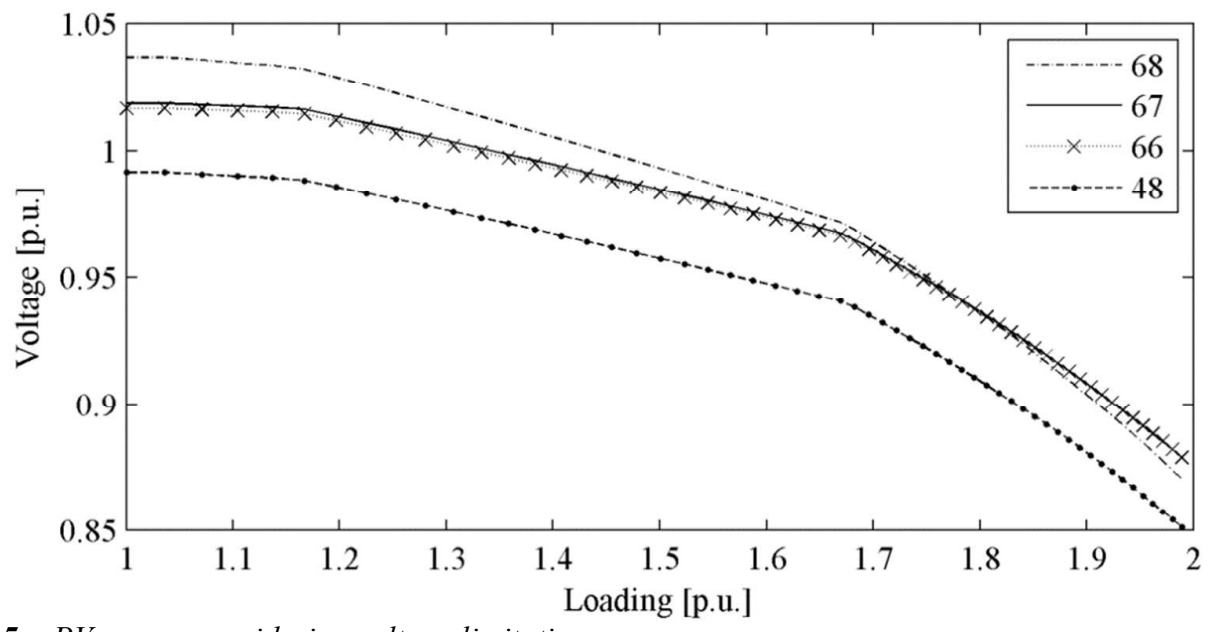

Fig. 5 PV curves considering voltage limitations

This study may be further enhanced by considering the active power limitation from the sources, as shown in Table 2. This consideration enables one to obtain Fig. 6. Such limitation makes the results even worse. Unlike the first case, when a load increase about $123 \%$ was observed, this time the system may sustain a $93 \%$ of load increase, which implies a large reduction in the load margin in comparison with the results depicted in Fig. 4.

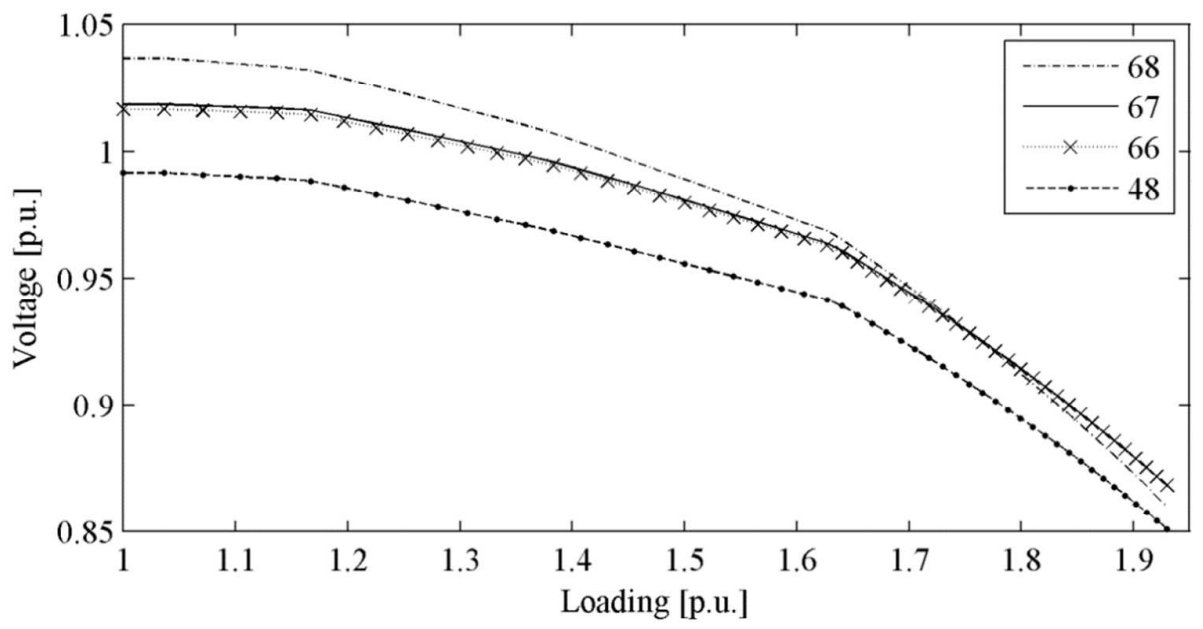

Fig. 6 PV curve with voltage level and active power generation constraints

The frequency variation may be monitored along the load increase pattern by applying (1). The result is displayed in Fig. 7, obtained under the same conditions as those applied to generate Fig. 6. It is important to note that (1) is associated to each inverter considered. Because, however, the system has only one frequency, Fig. 7 depicts the unified behaviour of the system frequency. Note that from the base case, the 
frequency is already smaller than $50 \mathrm{~Hz}$. As the system is further loaded and the inverters are demanded to supply more power, the frequency is further reduced beyond the lower limit of $49.5 \mathrm{~Hz}$. Note

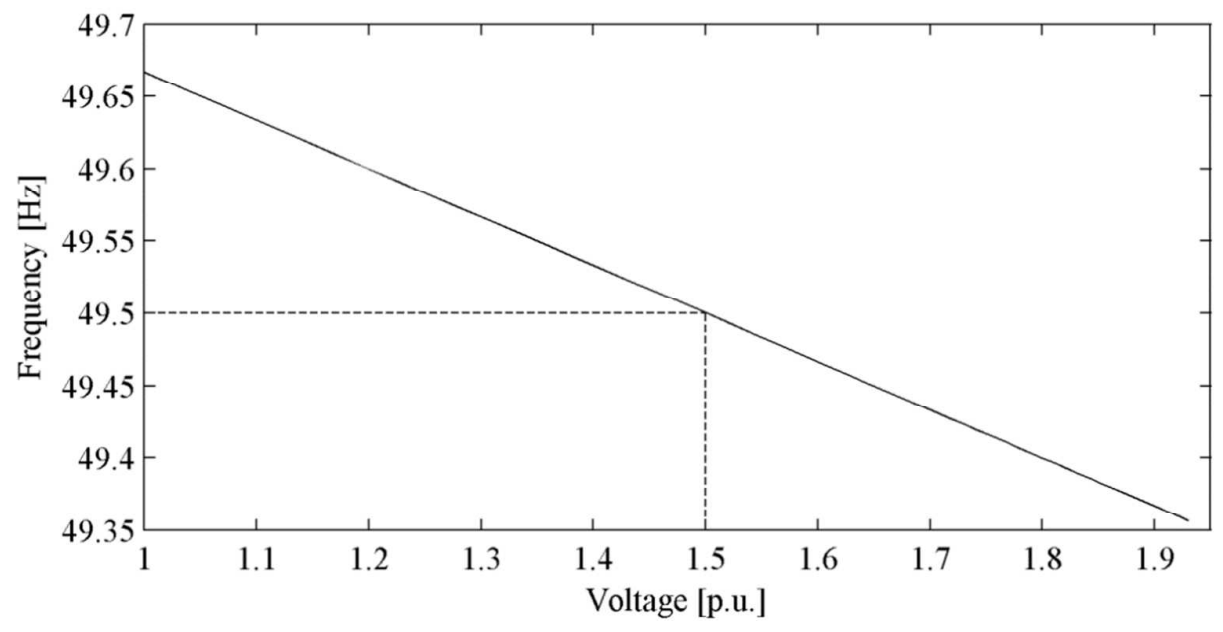

Fig. 7 Frequency variation as a function of load increase

that a deviation around $0.6 \mathrm{~Hz}$ is observed. For emergency conditions this may be acceptable. Note, however, that normally a maximum deviation of $0.5 \mathrm{~Hz}$ is allowed. This may be considered as another stopping criterion in the continuation process, rendering a system load margin around 1.5 p.u., even smaller than the one depicted in Fig. 6.

\subsection{Impact of disconnecting the intermittent sources}

The results described above are obtained when the intermittent sources operate at their maximum values. These results may worsen if the sources are assumed as out of operation, which is executed next.

The critical buses and the load margin are computed for this condition. The critical buses are displayed in Table 3, whereas the PV curves of some of them are depicted in Fig. 8.

Table 3: Critical buses with no intermittent sources considered

\begin{tabular}{|c|c|c|}
\hline & Base Case & Collapse \\
\hline \multirow{4}{*}{$\begin{array}{c}\text { Critical } \\
\text { Buses }\end{array}$} & 48 & 68 \\
\cline { 2 - 3 } & 47 & 67 \\
\cline { 2 - 3 } & 49 & 66 \\
\cline { 2 - 3 } & 50 & 48 \\
\cline { 2 - 3 } & 51 & 47 \\
\cline { 2 - 3 } & 68 & 49 \\
\hline
\end{tabular}




\begin{tabular}{|c|c|c|}
\hline & 46 & 50 \\
\hline $\begin{array}{c}\text { Load } \\
\text { Margin }\end{array}$ & & 1.8993 \\
\hline
\end{tabular}

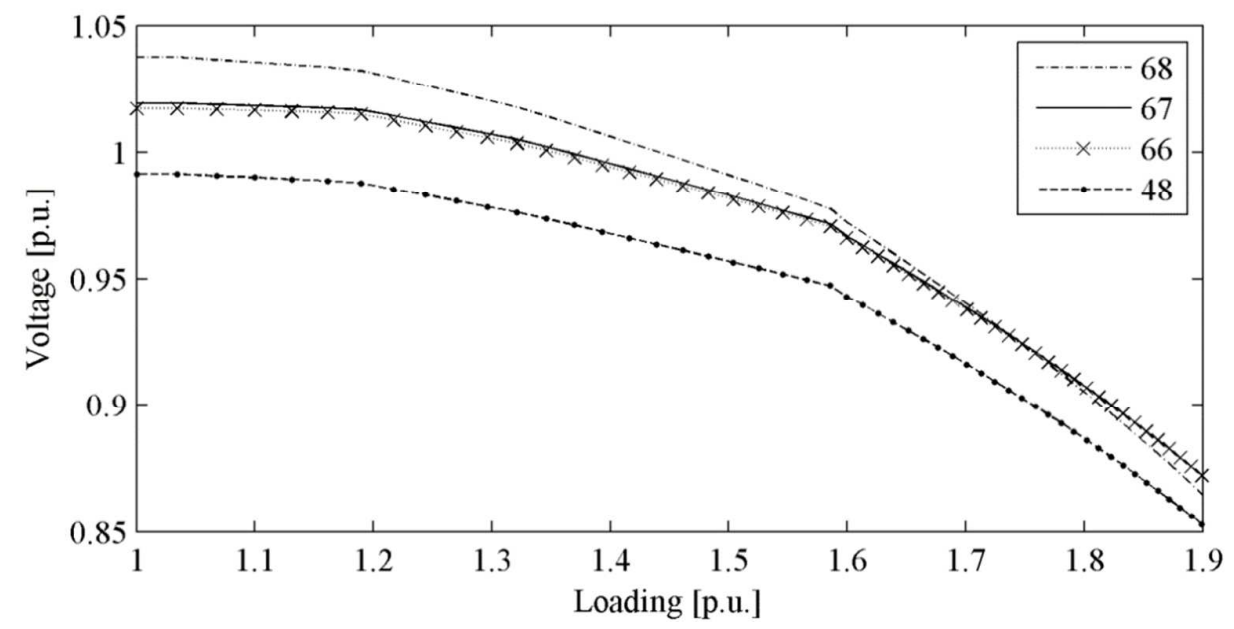

Fig. 8 PV curves with no intermittent generation

Note that removing the intermittent sources changes some of the critical buses at the point of collapse and reduces slightly the system load margin. This is an important feature to be considered in microgrids, since the availability of the intermittent sources depends on the weather conditions. In this test, undervoltage level stopped the process before underfrequency was detected.

\subsection{Effects of $m$ and $n$ variations}

The results discussed above are obtained by considering the coefficients $m$ and $n$ for the base case. Sensitivity with respect to these parameters is now tested. In this case, four different test conditions are considered as displayed in Appendix B. Then, the critical buses are evaluated at the base case and at the voltage collapse point, after the continuation method is executed. The results are shown in Table 4.

The idea in the tests depicted in Table 4 is to analyse how the output of each inverter affects the voltage profile and the system load margin. In this sense, the standard case is obtained when the coefficients $m$ and $n$ are the same for all the generating inverters. Because we focus on critical buses identification, frequency deviation and voltage level are considered as stopping criteria and play a crucial role in the process. Therefore, they are monitored as the system is loaded and justify the differences in the load margin obtained in the tests. Test 1 is done by increasing the coefficient $n$ and keeping $m$ as in the base case. Test 2 is a variation of Test 1 , since some coefficients $n$ are kept the same as in the base case, but five of them are dramatically increased. The expected effect of this increment is a reduction in the 
reactive power provided by these five units. Test 3 keeps $n$ as in the base case and increases $m$ in five generators, whereas Test 4 differs from the base case by increasing $m$ in only one generating unit. The aim of these last tests is to modify the active power sharing capacity of some units.

Table 4: Results obtained for different values of $\boldsymbol{m}$ and $\boldsymbol{n}$

\begin{tabular}{|c|c|c|c|c|c|c|c|c|c|c|}
\hline & \multicolumn{2}{|c|}{ Standard } & \multicolumn{2}{|c|}{ Test 1} & \multicolumn{2}{|c|}{ Test 2} & \multicolumn{2}{|c|}{ Test 3} & \multicolumn{2}{|c|}{ Test 4} \\
\hline \multirow{8}{*}{$\begin{array}{c}\text { Critical } \\
\text { Buses }\end{array}$} & Base & Collapse & Base & Collapse & Base & Collapse & Base & Collapse & Base & Collapse \\
\hline & 48 & 68 & 48 & 68 & 35 & 35 & 73 & 68 & 47 & 68 \\
\hline & 68 & 67 & 68 & 67 & 33 & 33 & 74 & 67 & 73 & 67 \\
\hline & 49 & 66 & 49 & 66 & 47 & 32 & 72 & 66 & 48 & 66 \\
\hline & 50 & 48 & 50 & 48 & 73 & 36 & 75 & 73 & 72 & 65 \\
\hline & 47 & 47 & 47 & 47 & 74 & 48 & 71 & 74 & 71 & 74 \\
\hline & 51 & 65 & 51 & 65 & 75 & 47 & 47 & 72 & 74 & 73 \\
\hline & 52 & 49 & 52 & 49 & 48 & 31 & 48 & 75 & 75 & 75 \\
\hline $\begin{array}{l}\text { Loading } \\
\text { Margin }\end{array}$ & \multicolumn{2}{|c|}{1.9297} & \multicolumn{2}{|c|}{2.1605} & \multicolumn{2}{|c|}{1.8740} & \multicolumn{2}{|c|}{1.6826} & \multicolumn{2}{|c|}{1.6236} \\
\hline
\end{tabular}

From Table 4 one can see that changing the droop coefficients may affect the results. The great difference in the coefficients $m$ renders Test 3 as the one with the least load margin. Note, however, that these coefficients have been varied randomly. An optimal search of these values is not addressed in this work.

\section{Conclusions}

This paper dealt with the problem of voltage collapse in microgrids. For this purpose, a Newton-based power flow method has been proposed, so some shortcomings of its applications in microgrids are overcome. The proposed methodology enables one to calculate a power flow with frequency and voltage deviations whereas incorporating the concept of a swing bus for this kind of systems. Renewable sources are also considered and the proposed methodology may handle both the connected and islanding modes of operation. Then, a continuation method is proposed by considering this power flow. For this sake, special attention is paid to the renewable sources, since they cannot vary their generation as considered to the dispatchable units. This paper investigated the role of the droop parameters, but a further important topic of study is the search of optimal values of these parameters. The presented results pertain to a practical system and show the proposed method to be effective for load margin calculation with several constraints. 
The method has also been tested by considering different coefficients responsible for the active and reactive power generation-share by the sources, enabling one to identify the impact of the coefficients aiming better operating points. The proposed method is robust and may handle a bunch of different operating constraints, providing a realistic load margin for planning and operating scenarios.

\section{Acknowledgment}

The authors thank CYTED programme (grant 713RT0475), CNPq, INERGE, CAPES, MINECO and FEDER founds (project ENE2012-37667-C02-02) for partially supporting this work.

\section{References}

1 Amin, M., 'Toward self-healing energy infrastructure systems', IEEE Computer Applications in Power, 14, (1), January 2001, pp. 20-28

2 El-hawary, M. E., 'The smart grid-State-of-the-art and future trends', Electric Power Components and Systems, 42(3-4), 2014, pp. 239-25

3 Chen, C., Duan, S., Cai, T., Liu, B., Hu, G., 'Smart energy management system for optimal microgrid economic operation', IET Renewable Power Generation, 5 (3), 2011, pp. 258 - 267

4 Carr, S., Premier, G. C., Guwy, A. J., Dinsdale, R. M., Maddy, J., 'Energy storage for active network management on electricity distribution networks with wind power', IET Renewable Power Generation, 8, (3), 2014, pp. 249 - 259

5 Butler-Purry, K.L., and Sarma, N.D.R., 'Self-healing reconfiguration for restoration of naval shipboard power systems', IEEE Trans. on Power Systems, 19, (2), May 2004, pp. 754-762

6 Bahrani, B., Saeedifard, M., Karimi, A., and Rufer, A., 'A multivariable design methodology for voltage control of a single-DG-unit microgrid', IEEE Trans. on Ind. Informatics, 9, (2), May 2013, pp. 589-599

7 Khaled, M., Abo-Al-Ez, Elaiw, A., Xia, X., 'A dual-loop model predictive voltage control/sliding-mode current control for voltage source inverter operation in smart microgrids', Electric Power Components and Systems, 42(3-4), 2014, pp. 348-360

8 Peças Lopes, J.A., Moreira, C.L., Madureira, A.G., 'Defining control strategies for microgrids islanded operation', IEEE Trans. on Power Systems, 21, (2), May 2006, pp. 916- 924 
9 Vasquez, J.C., Guerrero, J.M., Luna, A., Rodriguez, P., and Teodorescu, R., 'Adaptive droop control applied to voltage-source inverters operating in grid-connected and islanded modes', IEEE Trans. on Ind. Electron., 56, (10), October 2009, pp. $4088-4096$

10 Zamani, M. A., Yazdani, A., Sidhu, T.S., 'A control strategy for enhanced operation of inverterbased microgrids under transient disturbances and network faults', IEEE Trans. on Power Delivery, 27, (4), October 2012 , pp. 1737 - 1747

11 Salamah, A.M., Finney, S.J., Williams, B.W., 'Autonomous controller for improved dynamic performance of AC grid, parallel-connected, single-phase inverters', IET Generation, Transmission \& Distribution, 2, (2), 2008 , pp. $209-218$

12 Rokrok, E. ; Golshan, M.E.H., 'Adaptive voltage droop scheme for voltage source converters in an islanded multibus microgrid', IET Generation, Transmission \& Distribution, 4, 2010, pp. 562 $-578$

13 Tuladhar, A., Jin, H, Unger, T., and Mauch, K., 'Parallel operation of single phase inverter modules with no control interconnections,' Proc. IEEE-APEC’97 Conf., 1997, pp. 94-100

14 Guerrero, J.M., García de Vicuña, L., Matas, J., Castilla, M. and Miret, J. , 'A wireless controller to enhance dynamic performance of parallel inverters in distributed generation systems', IEEE Trans. on Power Eelectron., 19, (5), September 2004, pp. 1205-1213

15 Ahn, C., Peng, P., 'Decentralized voltage control to minimize distribution power loss of microgrids', IEEE Trans. on Smart Grids, 4, (3), 2013, pp. 1297 - 1304

16 Millar, R.J., Kazemi, S., Lehtonen, M., and Saarijarvi, E., 'Impact of MV connected microgrids on MV distribution planning', IEEE Trans. on Smart Grid, 3, (4), 2012 , pp. $2100-2108$

17 Nutkani, I.U., Loh P. C., Blaabjerg, F.,' Distributed operation of interlinked AC microgrids with dynamic active and reactive power tuning', IEEE Trans. on Industry Applications, 49, (5), 2013, pp. $2188-2196$

18 Shahnia, F., Chandrasena, R.P.S., Rajakaruna,S., Ghosh,A., 'Autonomous operation of multiple interconnected microgrids with self-healing capability', 2013 IEEE Power and Energy Society General Meeting (PES), 2013, pp. 1 - 5 
19 Alves, D. A., Silva, L. C. P., Castro, C. A., Costa, V. F., 'Parameterized fast decoupled load flows for tracing the power systems bifurcation diagrams,' 1999 Proc. IEEE PES Summer Meeting, pp. 708-713

20 Mohn, F. W., Zambroni de Souza, A. C., 'Tracing PV and QV curves with the help of a CRIC continuation method,' IEEE Trans. on Power Systems, 21, p. 1104-1114, 2006

21 Clement-Nyns, K., Haesen, E., Driesen, J., 'The impact of vehicle-to-grid on the distribution grid,' Electric Power Systems Research, 81, pp. 185-192, 2011

22 Oliveira, D.Q., Zambroni de Souza, A.C., Delboni, L.F.N., 'Optimal plug-in hybrid electric vehicles recharge in distribution power systems', Electric Power Systems Research, 98, pp. 7785,2013

23 Li Zhu, Yu, F.R., Bin Ning, Tao Tang, 'Stochastic charging management for plug-in electric vehicles in smart microgrids fueled by renewable energy sources', IEEE 2011 Online Conference on Green Communications (GreenCom), 2011, pp. 7 - 12

24 Ashrafi, A., Shahrtash, S.M., 'Dynamic control strategy in power system based on multi-agent system', 2013, pp. $173-180$

25 Díaz, G., 'Maximum loadability of droop regulated microgrids - formulation and analysis', IET Generation, Transmission \& Distribution, 7, (2), 2013 , pp. 175 - 182

26 Abdelaziz, M. M. A., Farag, H. E., El-Saadany, E. F., Mohamed, Y, A. I. 'A Novel and Generalized Three-Phase Power Flow Algorithm for Islanded Microgrids Using a Newton Trust Region Method', IEEE Trans. on Power Systems, 28 (1), 2013, pp. 190-201

27 Rese, L., Simões Costa, A., Silva, A. S. 'A Modified Load Flow Algorithm for Microgrids Operating in Islanded Mode', IEEE PES Innovative Smart Grid Technologies Latin America (ISGT LA), 2013, April 15-17, São Paulo, Brazi

28 Hassan, M.A.; Abido, M.A., 'Optimal Design of Microgrids in Autonomous and GridConnected Modes Using Particle Swarm Optimization‘, IEEE Trans. on Power Electronics, 26 (3), March 2011, pp.755-769

29 Elrayyah, A., Sozer, Y., Elbuluk, M. E., 'A Novel Load-Flow Analysis for Stable and Optimized Microgrid Operation', IEEE Trans. on Power Delivery, 29 (4), 2014, pp. 1709-1717

30 Bollman, A. M. 'An experimental study of frequency droop control in a low-inertia microgrid', Master Thesis, University of Illinois, 2009 
31 Monticelli, A. 'State estimation in electric power systems: A generalized approach', Springer, 1999

32 Almeida, A.B.; Valença de Lorenci, E.; Coradi Leme, R.; Zambroni de Souza, A.C.; Lima Lopes, B.I.; Kwok Lo, 'Probabilistic voltage stability assessment considering renewable sources with the help of the PV and QV curves,' IET Renewable Power Generation, 7(5), 2013, pp. 521,530 .

33 Lourenco, E.M., Loddi, T., Tortelli, O.L, 'Unified load flow analysis for emerging distribution systems', Innovative Smart Grid Technologies Conference Europe (ISGT Europe), Gothenburg, 2010, pp. 11-13

\section{Appendix A}

The micro grid employed in the tests is depicted below:

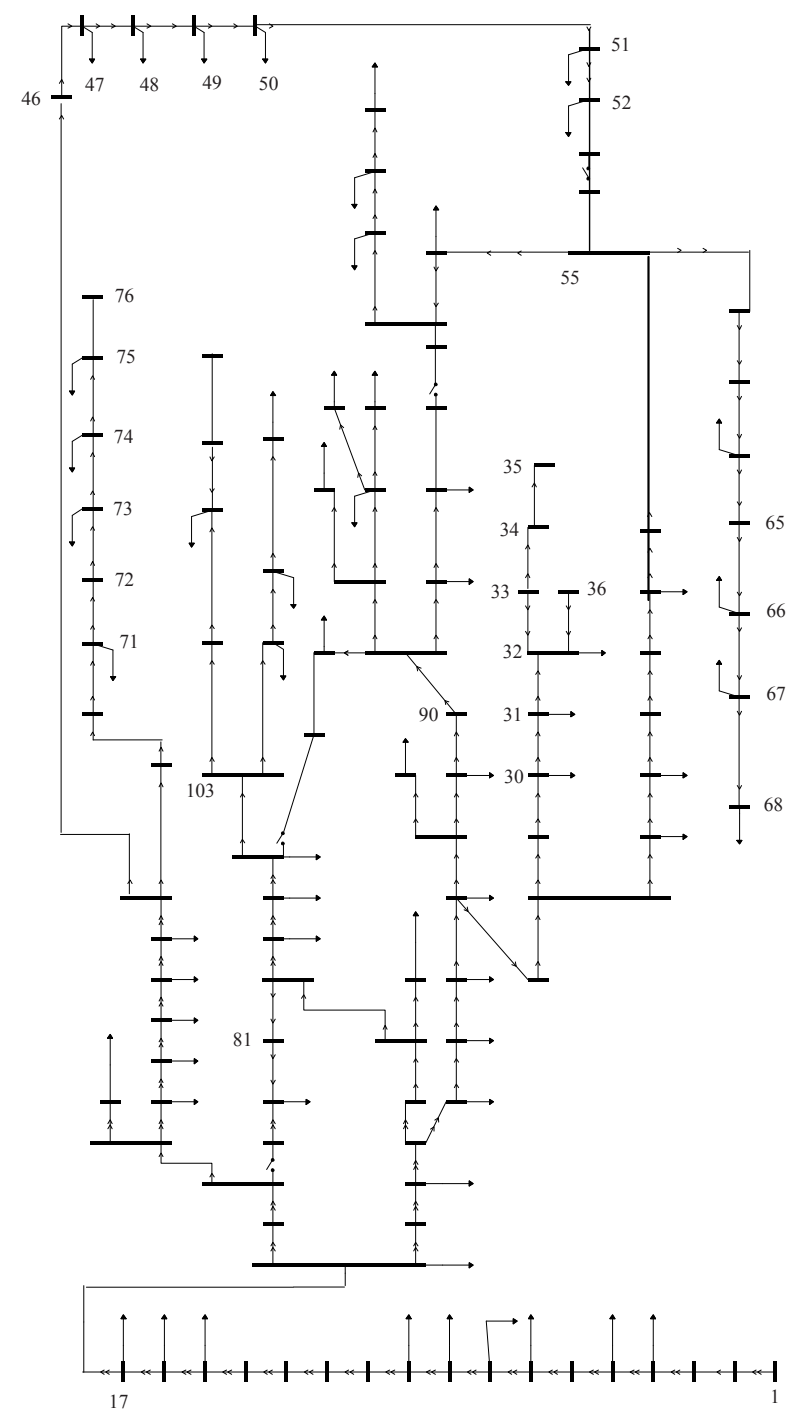




\section{Appendix B}

The $m$ and $n$ coefficients used in test results section are described in Table B1.

Table B1: Values for $m$ and $n$ used in the tests

\begin{tabular}{|c|c|c|c|}
\hline Test Case & $\mathbf{m}$ & $\mathbf{n}$ & Bus Numbers \\
\hline 1 & $m_{b}$ & $100 \times n_{b}$ & $34,46,55,65,76,81,90,103$ \\
\hline \multirow{2}{*}{2} & $m_{b}$ & $1000 \times n_{b}$ & $34,76,81,90,103$ \\
\cline { 2 - 4 } & $m_{b}$ & $n_{b}$ & $46,55,65$ \\
\hline \multirow{2}{*}{3} & $10 \times m_{b}$ & $n_{b}$ & $34,65,81,90,103$ \\
\cline { 2 - 4 } & $m_{b}$ & $n_{b}$ & $46,55,76$ \\
\hline \multirow{2}{*}{4} & $m_{b}$ & $n_{b}$ & 65 \\
\cline { 2 - 4 } & $m_{b}$ & $n_{b}$ & $34,46,55,76,81,90,103$ \\
\hline
\end{tabular}




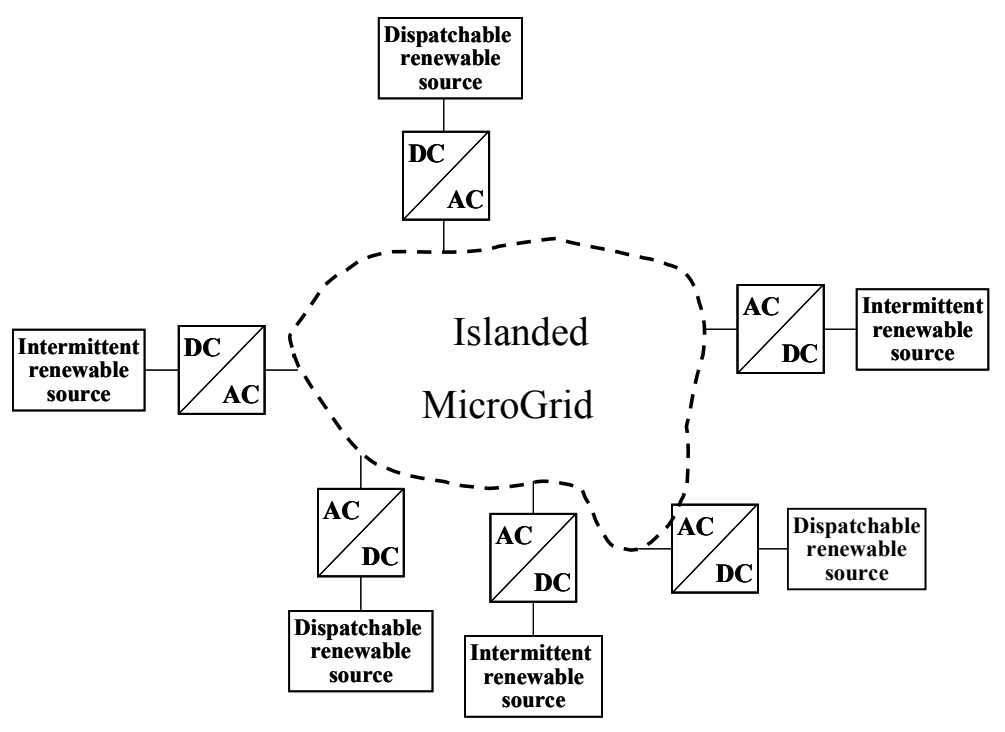

Fig 1 General diagram of a microgrid with electronically-coupled renewable energy sources

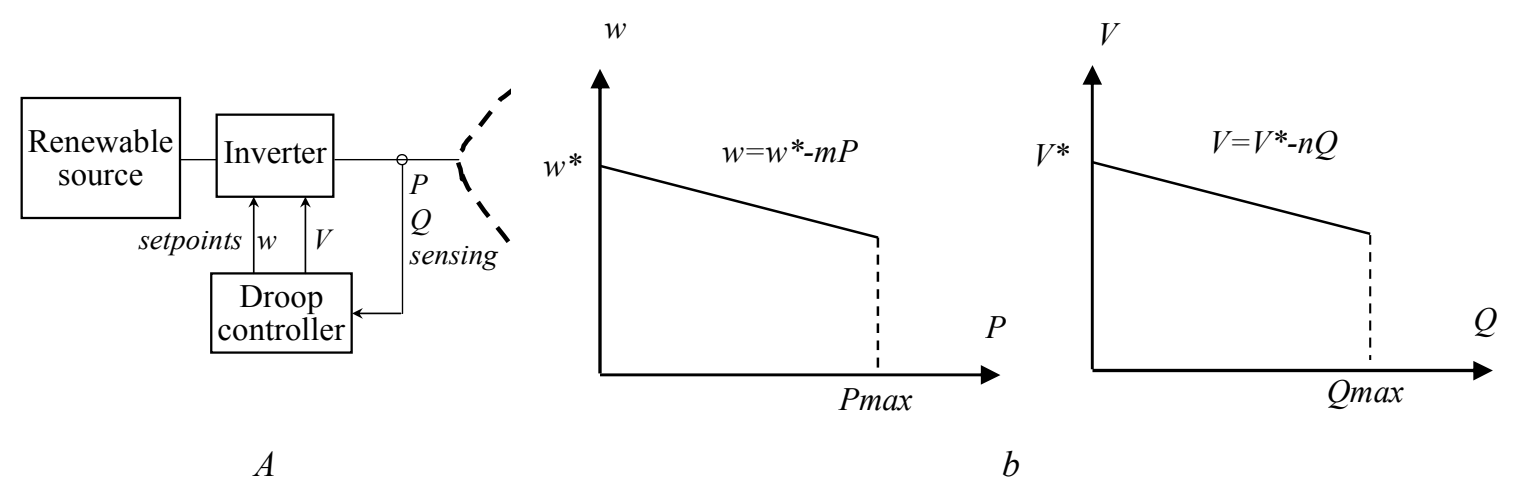

Fig 2 Droop method for the dispatchable generation inverters (a-General diagram of the dispatchable energy source, $b$ - Representation of the droop method curves) 


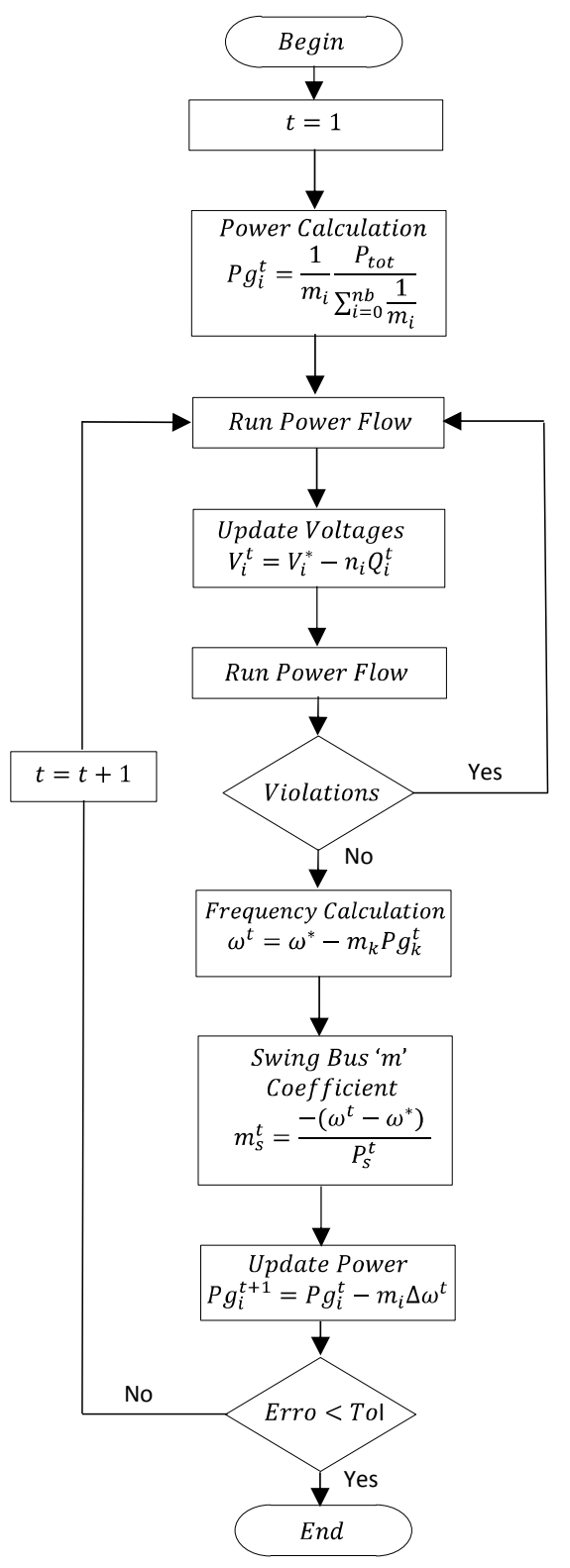

Fig 3 Flowchart of the proposed algorithm 


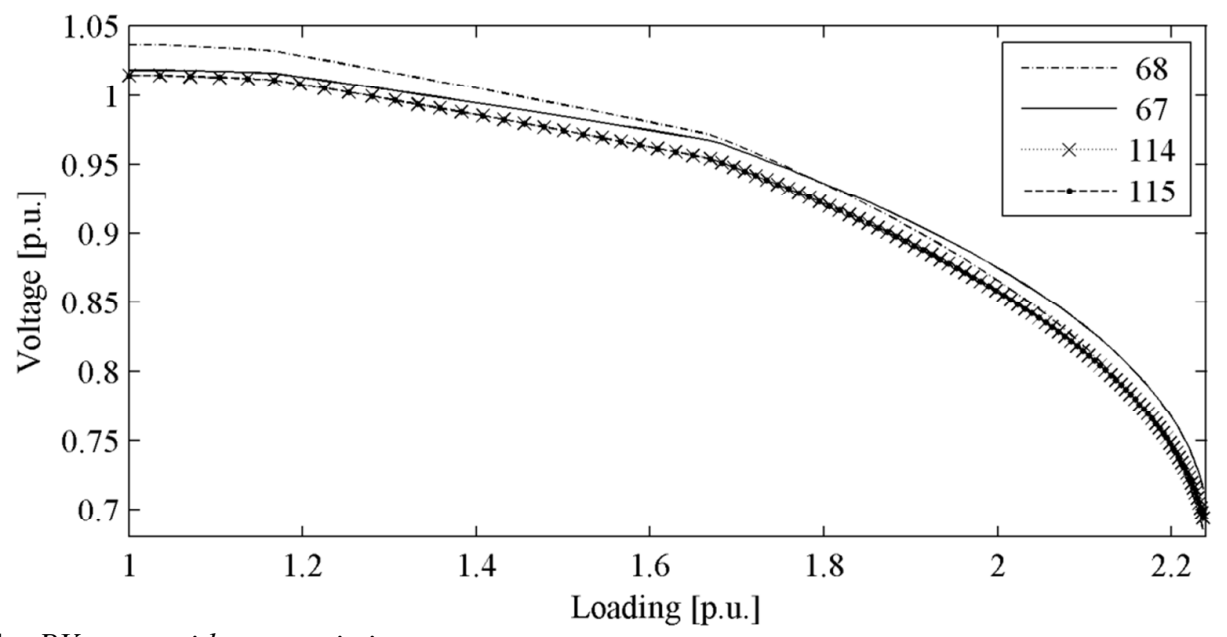

Fig. 4 PV curve with no restrictions

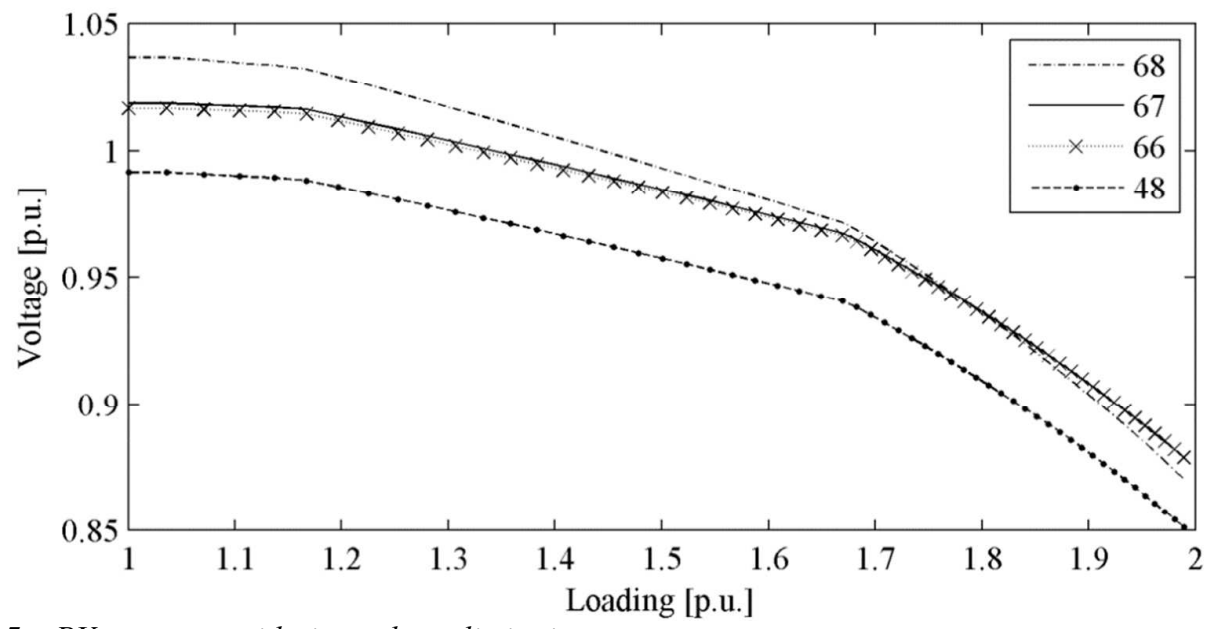

Fig. 5 PV curves considering voltage limitations

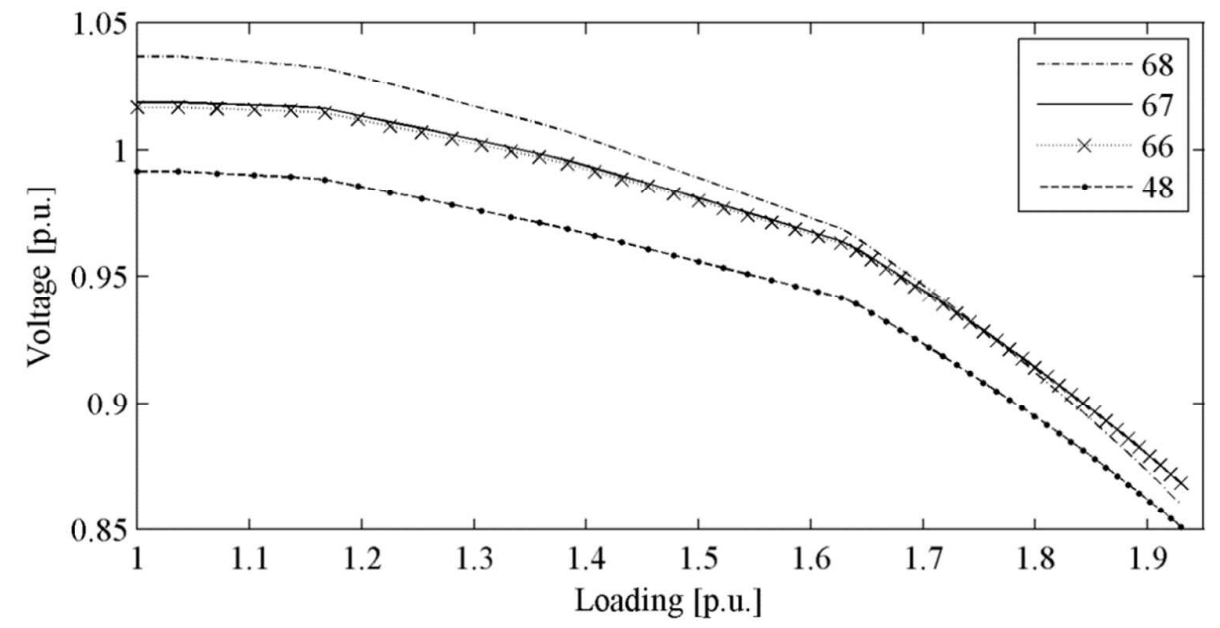

Fig. 6 PV curve with voltage level and active power generation constraints 


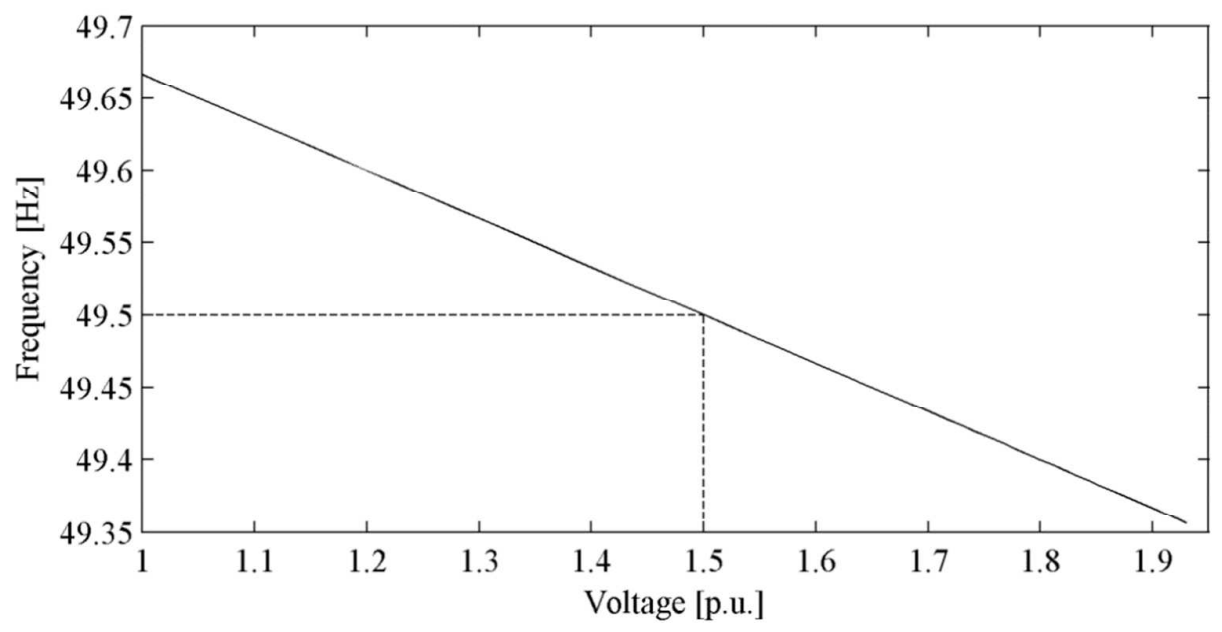

Fig. 7 Frequency variation as a function of load increase

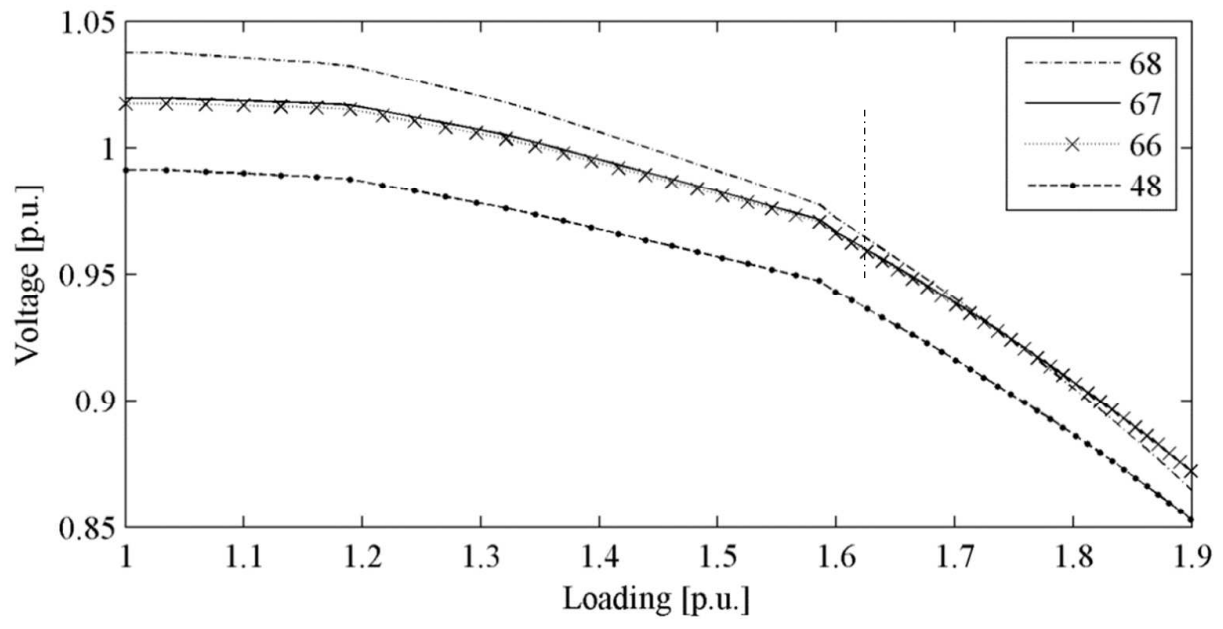

Fig. 8 PV curves with no intermittent generation 
Appendix A

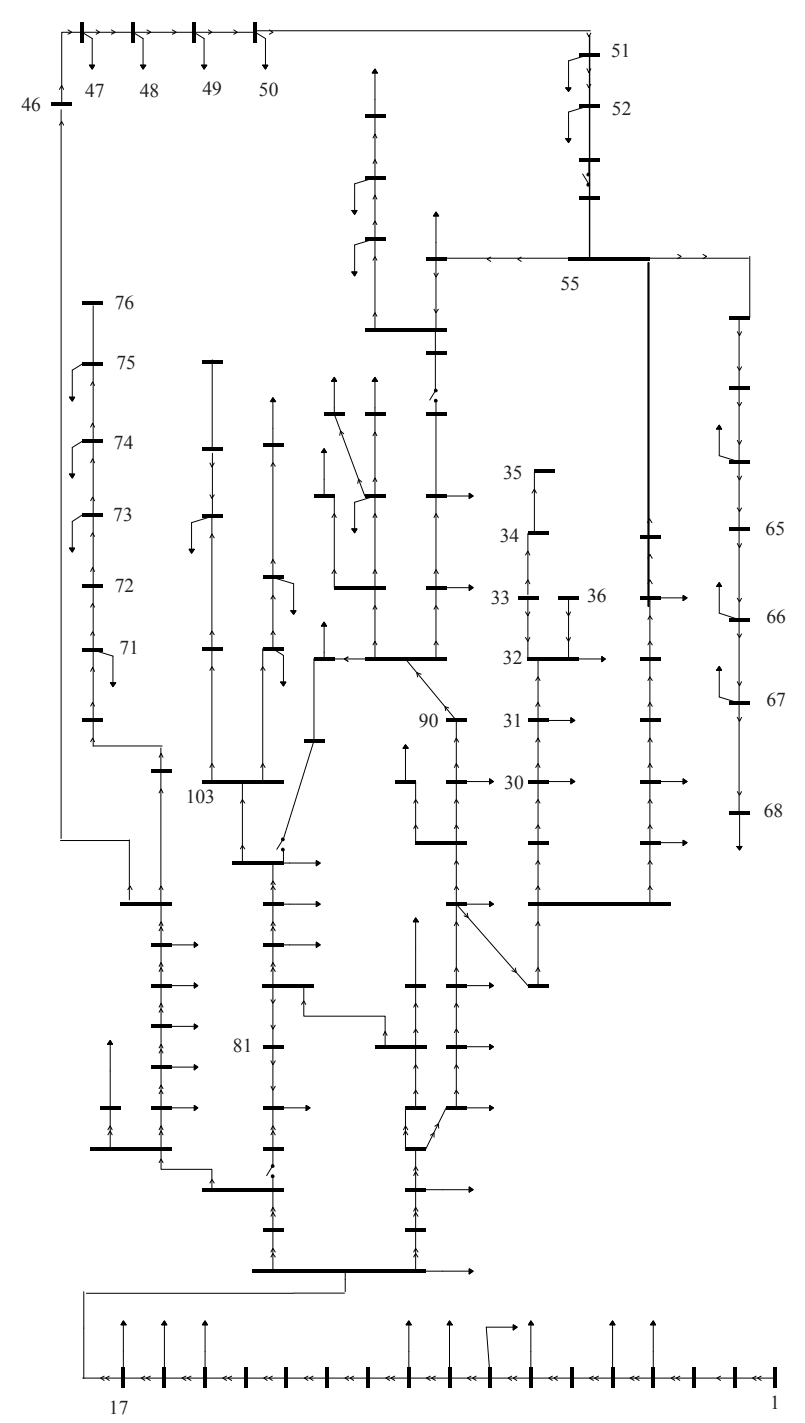


Table 1: Capacity of the intermittent energy sources considered

\begin{tabular}{|c|c|c|}
\hline Bus & Type & $\begin{array}{c}\text { Cap. } \\
\text { [p.u.] }\end{array}$ \\
\hline 49 & Solar & $3 \mathrm{e}-3$ \\
\hline 50 & Solar & $3 \mathrm{e}-3$ \\
\hline 71 & Wind & $20 \mathrm{e}-3$ \\
\hline 72 & Wind & $20 \mathrm{e}-3$ \\
\hline 73 & Wind & $20 \mathrm{e}-3$ \\
\hline
\end{tabular}

Table 2: Characteristics of the dispatchable energy sources considered

\begin{tabular}{|c|c|c|c|}
\hline Bus & $\boldsymbol{m}$ & $\boldsymbol{n}$ & $\begin{array}{c}\text { Max } \boldsymbol{P} \\
\text { [p.u.] }\end{array}$ \\
\hline 34 & $1 \mathrm{e}-3$ & $0.1 \mathrm{e}-3$ & 0.6 \\
\hline 46 & $1 \mathrm{e}-3$ & $0.1 \mathrm{e}-3$ & 0.6 \\
\hline 55 & $1 \mathrm{e}-3$ & $0.1 \mathrm{e}-3$ & 0.6 \\
\hline 65 & $1 \mathrm{e}-3$ & $0.1 \mathrm{e}-3$ & 0.3 \\
\hline 76 & $1 \mathrm{e}-3$ & $0.1 \mathrm{e}-3$ & 0.6 \\
\hline 81 & $1 \mathrm{e}-3$ & $0.1 \mathrm{e}-3$ & 0.6 \\
\hline 90 & $1 \mathrm{e}-3$ & $0.1 \mathrm{e}-3$ & 0.6 \\
\hline 103 & $1 \mathrm{e}-3$ & $0.1 \mathrm{e}-3$ & 0.6 \\
\hline
\end{tabular}

Table 3: Critical buses with no intermittent sources considered

\begin{tabular}{|c|c|c|}
\hline & Base Case & Collapse \\
\hline \multirow{4}{*}{$\begin{array}{c}\text { Critical } \\
\text { Buses }\end{array}$} & 48 & 68 \\
\cline { 2 - 3 } & 47 & 67 \\
\cline { 2 - 3 } & 49 & 66 \\
\cline { 2 - 3 } & 50 & 48 \\
\cline { 2 - 3 } & 68 & 47 \\
\cline { 2 - 3 } & 46 & 49 \\
\hline $\begin{array}{c}\text { Load } \\
\text { Margin }\end{array}$ & & 50 \\
\hline
\end{tabular}


Table 4: Results obtained for different values of $\boldsymbol{m}$ and $\boldsymbol{n}$

\begin{tabular}{|c|c|c|c|c|c|c|c|c|c|c|}
\hline & \multicolumn{2}{|c|}{ Standard } & \multicolumn{2}{|c|}{ Test 1} & \multicolumn{2}{|c|}{ Test 2} & \multicolumn{2}{|c|}{ Test 3} & \multicolumn{2}{|r|}{ Test 4} \\
\hline \multirow{8}{*}{$\begin{array}{c}\text { Critical } \\
\text { Buses }\end{array}$} & Base & Collapse & Base & Collapse & Base & Collapse & Base & Collapse & Base & Collapse \\
\hline & 48 & 68 & 48 & 68 & 35 & 35 & 73 & 68 & 47 & 68 \\
\hline & 68 & 67 & 68 & 67 & 33 & 33 & 74 & 67 & 73 & 67 \\
\hline & 49 & 66 & 49 & 66 & 47 & 32 & 72 & 66 & 48 & 66 \\
\hline & 50 & 48 & 50 & 48 & 73 & 36 & 75 & 73 & 72 & 65 \\
\hline & 47 & 47 & 47 & 47 & 74 & 48 & 71 & 74 & 71 & 74 \\
\hline & 51 & 65 & 51 & 65 & 75 & 47 & 47 & 72 & 74 & 73 \\
\hline & 52 & 49 & 52 & 49 & 48 & 31 & 48 & 75 & 75 & 75 \\
\hline $\begin{array}{l}\text { Loading } \\
\text { Margin }\end{array}$ & \multicolumn{2}{|c|}{1.9297} & \multicolumn{2}{|c|}{2.1605} & \multicolumn{2}{|c|}{1.8740} & \multicolumn{2}{|c|}{1.6826} & \multicolumn{2}{|c|}{1.6236} \\
\hline
\end{tabular}

\section{Appendix B}

Table B1: Values for $m$ and $n$ used in the tests

\begin{tabular}{|c|c|c|c|}
\hline Test Case & $\mathbf{m}$ & $\mathbf{n}$ & Bus Numbers \\
\hline 1 & $m_{b}$ & $100 \times n_{b}$ & $34,46,55,65,76,81,90,103$ \\
\hline \multirow{2}{*}{2} & $m_{b}$ & $1000 \times n_{b}$ & $34,76,81,90,103$ \\
\cline { 2 - 4 } & $m_{b}$ & $n_{b}$ & $46,55,65$ \\
\hline \multirow{2}{*}{3} & $10 \times m_{b}$ & $n_{b}$ & $34,65,81,90,103$ \\
\cline { 2 - 4 } & $m_{b}$ & $n_{b}$ & $46,55,76$ \\
\hline \multirow{2}{*}{4} & $m_{b}$ & $n_{b}$ & 65 \\
\cline { 2 - 4 } & $m_{b}$ & $n_{b}$ & $34,46,55,76,81,90,103$ \\
\hline
\end{tabular}

